\title{
EFFECTS OF SOWING DATE AND GENOTYPE ON OIL CONTENT AND MAIN FATTY ACID COMPOSITION IN CAMELINA [Camelina sativa L. (Crantz)]
}

\author{
Orhan KURT ${ }^{*}$, Merve GORE \\ Ondokuz Mayis University, Faculty of Agriculture, Department of Field Crops, Samsun, TURKEY \\ *Corresponding author: orhank@omu.edu.tr
}

Received: 23.09.2020

\begin{abstract}
The objective of the research was to determine the effects of genotype and sowing date on oil content and composition of the main fatty acids of spring-seeded camelina. Depending on the sowing time, the change of oil content and main fatty acids such as palmitic, stearic, oleic, linoleic, linolenic, eicosenoic and erusic acid content are 26.65-33.65\%, 6.04-7.08\%, 2.04-3.15\%, 16.63-18.84\%, 24.51-25.16\%, 29.57-31.69\%, 14.30-15.04\% and $1.10-1.86 \%$, respectively. When the sowing time is delayed; oil content, stearic, linoleic, linolenic and erusic acid content decreased in contrast palmitic, oleic and eicosenoic acid content increased. The effect of sowing time on genotypes is important in terms of the evaluated characters. The PI-650142 genotype is more tolerant than PI-304269 genotype against the effects of environmental factors. Consequently, in case of delay of sowing time, it is extremely important to perform timely sowing, considering the changes in both oil content and fatty acids compositions. In case of delayed sowing for any reason, varieties that can tolerate the effects that may arise due to delay should be preferred. Thus, the losses that may arise can be reduced, albeit partially.
\end{abstract}

Keywords: Camelina, fatty acid composition, oil content, omega-3, sowing time

\section{INTRODUCTION}

Besides being used in human and animal nutrition, oils are used as raw materials in the industry. While the oil used in industry is desired to be rich in linolenic (omega3 ) and erusic fatty acids, the edible oil used in human nutrition is desired to be rich in oleic (omega-9) and linoleic (omega-6) fatty acids. There are many plants in the world where a high amount of oil is obtained from its seed. However, the number of oilseed plants that have the quality of oil that can meet the demands of different consumer groups and can adapt to different ecological regions is limited (Weiss, 2000). The importance of camelina plant in this area has increased in recent years due to its high oil content and quality fatty acid composition, which can be used as a raw material in the energy sector, especially in biofuel. Camelina sativa L. is a member of the Brassicaceae family and is the only species of economic importance in the Camelina genus (Gore and Kurt, 2017). Camelina oil contains about 5$10 \%$ saturated fatty acids and $90-95 \%$ unsaturated fatty acids. While the most important saturated fatty acids in Camelina are palmitic (5-8\%) and stearic (3-5\%) acid, the most important unsaturated fatty acids are oleic (15-20\%), linoleic (15-20\%), linolenic acid (35-45\%) and eicosenoic $(15-18 \%)$ acid. It also contains a small amount of erucic acid (2-4\%) (Gore and Kurt, 2017).
The composition of fatty acids in oilseeds is not fixed and can be affected by cultural practices as well as genetic, ecological, morphological and physiological factors (Garcia-Inzaet et al., 2014; Popa et al., 2017). It is very important to know under which conditions the composition of fatty acids may change in terms of oil quality. Among all environmental factors, the temperature during the flowering and seed maturing period plays the main role in determining the composition of fatty acids.

Temperature is generally considered one of the main factors affecting the biosynthesis of polyunsaturated fatty acids. The increasing air temperature during the flowering period and seed development stage reduce the oil content of the seed (Omidi et al., 2010) and the composition of unsaturated fatty acids (Schulte et al., 2013; Jiang et al., 2014).

Seed sowing time is important in terms of influencing whether the flowering and seed filling periods coincide with warmer days. Early sowing contributes to the formation of higher oil content by providing a longer seed filling period (Gesch and Cermak, 2011). Increasing air temperature with the delay of the seed sowing date causes a shorter growth period between sowing and flowering. Correspondingly, the temperature stress causes the number of fertile flowers and consequently the number of capsules with a full-grain to decrease and the capsule sizes 
to be less (Farre et al., 2002; Adamsen and Coffelt, 2005). In addition, late sowing date increases oleic and linoleic acid content but causes a decrease in linolenic acid content (Pavlista et al., 2011). Water stress, which occurs as a result of increased drought, plays a role in changing the composition of fatty acids (Pritchard et al., 2000). Drought conditions increase the oleic/linoleic acid ratio (Sainz et al., 1999).

The oil content of camelina seed and the fatty acid composition may vary between genotype and different environmental conditions (Vollmann et al., 2007; Righini, 2018). For example, the oil content of the camelina has been reported to be 32.1-33.4\% in winter sowing and 24.3-35.1\% in summer sowing (Kinay et al., 2019). Environmental factors such as temperature, precipitation, day length and light intensity play an important role in the fatty acid composition, especially affecting polyunsaturated fatty acid content (Zubr, 2003). For example, it has been reported that the linoleic acid content, which is $40.3 \%$ in cold climates, decreased to $34.7 \%$ in warmer climates (Sipalova et al., 2011; Kirkhus et al., 2013). In addition, the oil content was reported to increase from $26 \%$ in Southern Europe to $43 \%$ in Northern Europe, while linoleic acid ratio dropped from $25.9 \%$ in Southern Europe to $20.3 \%$ in Northern Europe Depending on the physiological parameters, sowing time is a very important agricultural practice that must be emphasized precisely because it affects the content of the oil in the seed, the amount and quality of the oil and the composition of the fatty acids. However, a limited number of studies have been conducted on camelina to determine the effects of seed sowing date and the effects of genotype, especially on the composition of fatty acids.

In camelina, it is determined that delay in sowing in the spring season has a negative effect on the oil content and biodiesel oil quality (Neupane et al., 2019). It has also reported that when sowing is done early in the spring season, higher oil content (32-34\%) is obtained depending on the genotype (Sintim et al., 2016). It has been determined that high temperatures occurring during the flowering period while increasing the oleic and linoleic acid ratio, decrease the oil yield. In addition, depending on the genotype, it has been determined that the oil content is between $36.47-41.44 \%$, the oleic acid content is 12.74 $17.94 \%$, the linoleic acid content is $14.74-23.25 \%$, the linolenic acid content is $27.00-38.08 \%$ and the eicosenoic acid content is 12.81-14.50\% (Righini et al., 2019).

To produce high-quality camelina seeds containing high amounts of oil, it is extremely important to determine how the interaction of both genotypic and environmental parameters, as well as genotypic and environmental parameters, affects the content and fatty acid composition of the camelina seed. Taking this importance into consideration, this research was carried out to determine the effects of sowing time and genotype on camelina oil content and mainly saturated and unsaturated fatty acid compositions.

\section{MATERIALS AND METHODS}

\section{Material}

In the study, PI-650142 (Denmark) and PI-304269 (Sweden) camelina genotypes provided from USDA were used (Anon, 2020a). As a result of the preliminary researches, these genotypes were used in this study because there are two genotypes that provide the best adaptation to the research field in terms of yield and yield elements.

\section{Experimental Area}

Field experiment was conducted at Samsun-Turkey $\left(41^{\circ} 37.49^{\prime} \mathrm{N}, 35^{\circ} 36^{\prime} 30^{\prime \prime} \mathrm{E}\right)$ in spring vegetation in 2017 and 2018. The data of the monthly average temperature, day length, precipitation and relative humidity throughout the research period and long term are given in Figure 1. Monthly average temperature, day length and humidity values are higher than the average of the experiment in the $2^{\text {nd }}$ year (2018), $1^{\text {st }}$ year (2017) and long years. Monthly average precipitation values are lower than the average of long years in both years of the experiment. In the first year of the experiment, there was no rainfall in July (Figure 1).

The soil structure of the experiment area is clay loam, its organic substance $(2.83 \%)$ and nitrogen content are moderate, $\mathrm{K}_{2} \mathrm{O}$ concentration is high (exchangeable $\mathrm{K}$ $7.59 \mathrm{~kg} \mathrm{ha}^{-1}$ ), $\mathrm{P}_{2} \mathrm{O}_{5}$ concentration is medium (available $\mathrm{P}$ $0.66 \mathrm{~kg} \mathrm{ha}^{-1}$ ), lime content $1.73 \%$ and soil $\mathrm{pH}$ is 7.71 .

\section{Method}

The experiment was arranged in a split-plot design with three replicates, in which varieties (PI-650142 and PI-304269) were set up as the main plot, whereas sowing dates as the sub-plot. Sowing dates were arranged at May 1st, May 11st, May 21st and May 31st during the 2017 and the 2018 spring seasons, respectively. Plot size was $3 \times 1 \mathrm{~m}$ with spacing of $20 \mathrm{~cm}$ row distance and $5 \mathrm{~cm}$ plant distance in each rows. In both years of the experiment period; $40 \mathrm{~kg} \mathrm{ha}^{-1}$ of ammonium nitrate fertilizer was applied before flowering. Weed control was carried out twice, before the stalk and during the flowering period. Field capacity irrigation was carried out on 1 July in the first year and on 12 June and 11 July in the second year. The harvest was done in both years when $90 \%$ of the capsules were mature. 

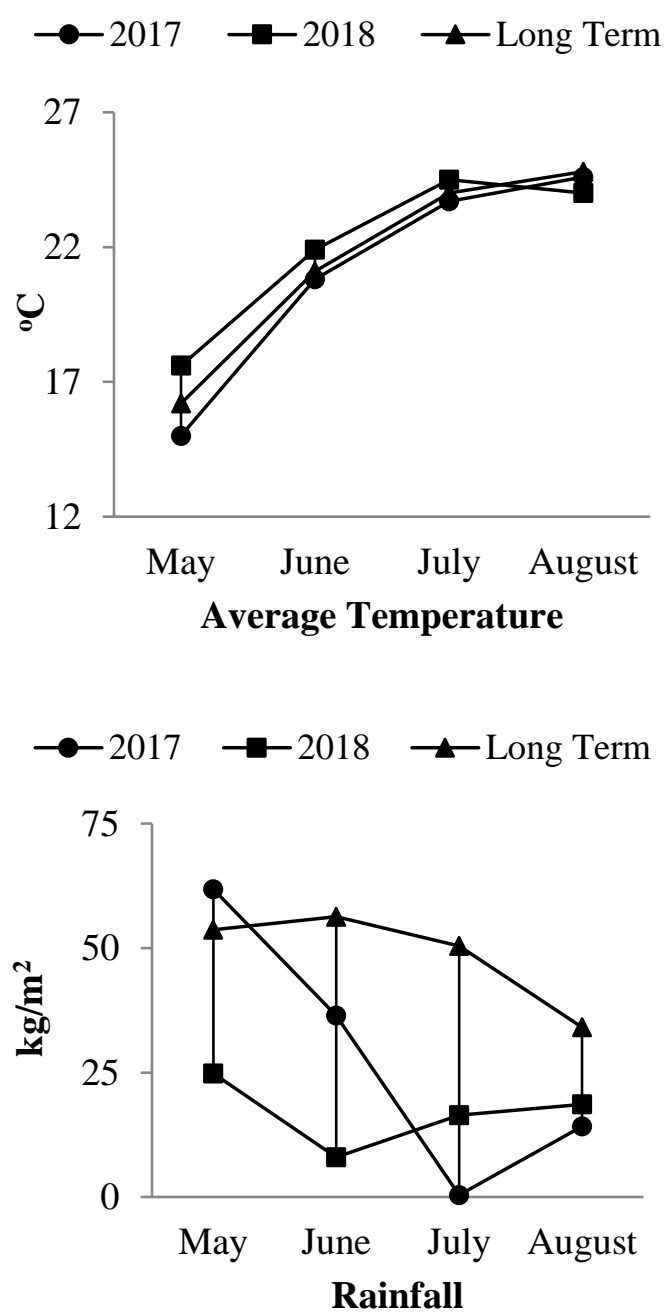
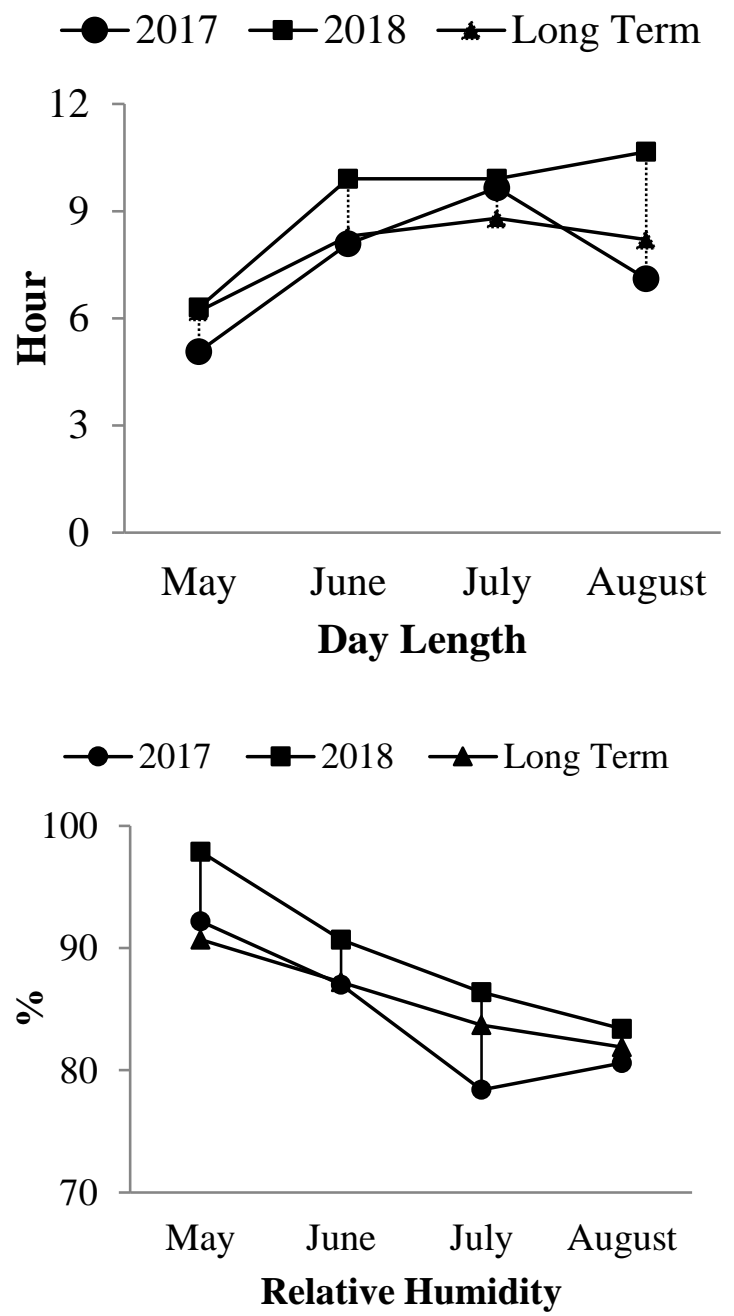

Figure 1. The average monthly air temperature, day length, rainfall and relative humidity recorded during camelina growing season in 2017 and 2018 (Anon, 2020b).

\section{Determination of Oil Content and Fatty Acids Compositions}

Oil content analysis was performed using the Ankom XT15 Soxhlet Extraction System according to the method reported by AOCS 5-04 (Anon, 2020c). The fatty acid analysis was performed using Shimadzu 2010 Gas Chromatograph (Kurt et al., 2011). The capillary column was $20 \mathrm{mx} 0.25 \mathrm{~mm}$ with a film thickness of $0.10 \mu \mathrm{m}$. Nitrogen $\left(\mathrm{N}_{2}\right)$ gas was used as the carrier gas, the pressure of the carrier gas was set to $175 \mathrm{kPa}$ colon. Injection, detector, and oven temperatures were 250, 260, and 190 ${ }^{\circ} \mathrm{C}$, respectively. Software GC solution was used for data analysis. Quantitative analysis of FA in camelina samples was accomplished by comparison with FAME Mix standard. The conversation from FAME to fatty acids was performed using coefficient, which was calculated as the ratio of the molecular weight of fatty acid to the molecular weight of fatty acid methyl ester.

\section{Data Calculation and Statistical Analysis}

The data were analysed according to Gomez and Gomez (1984) using SPSS 17,0 statistical software. The means of treatments were compared by DUNCAN's Multiple Range Test at 5\% and $1 \%$ probability level (Gomez and Gomez, 1984).

\section{RESULTS AND DISCUSSION}

\section{Oil Content}

Oil content was significantly $(p<0.01)$ affected by year, genotype, sowing time and their interactions (Table 1). When the data of the two years are evaluated together, the oil content decreased as the sowing time was delayed, and the oil content, which was $33.65 \%$ at the first sowing time, decreased to $26.65 \%$ at the 4 th sowing time. The oil content was $33.85 \%$ in 2017 and $25.39 \%$ in 2018, with the reduction in fat content being $24.99 \%$ (Table 2 ). When the average of the years is evaluated together, the decrease in 
oil content was $14.09 \%$ (from $36.26 \%$ to $31.15 \%$ ) in 2017 , while it was $28.61 \%$ (from $31.04 \%$ to $22.16 \%$ ) in 2018 (Table 2; Figure 2a). The average oil content was $28.96 \%$ in the PI-650142 genotype and $30.28 \%$ in the PI-304269 genotype, and the oil content decreased in both genotypes as the sowing was delayed in both years. This decrease; In
2017 , it was $11.43 \%$ (from $35.34 \%$ to $31.30 \%$ ) in the PI650142 genotype and $16.64 \%$ (from $37.19 \%$ to $31.00 \%$ ) in the PI-304269 genotype, while in 2018, it was $13.71 \%$ (from $27.65 \%$ to $23.86 \%$ ) in the PI-650142 genotype and $40.58 \%$ (from $34.43 \%$ to $20.46 \%$ ) in the PI-304269 genotype.

Table 1. F values of variance analysis of the oil content and composition of fatty acids of two camelina genotypes evaluated under different sowing times

\begin{tabular}{|c|c|c|c|c|c|c|c|c|c|}
\hline \multirow{2}{*}{ Source of Variation } & \multirow{2}{*}{ df } & \multirow{2}{*}{ Oil Content } & \multicolumn{2}{|c|}{ Saturated Fatty Acids } & \multicolumn{5}{|c|}{ Unsaturated Fatty Acids } \\
\hline & & & Palmitic & Stearic & Oleic & Linoleic & Linolenic & Eicosenoic & Erucic \\
\hline Years $(Y)$ & 1 & $1359.09 * *$ & $157.25 * *$ & $56.31 * *$ & $761.10 * *$ & $3203.95 * *$ & $12.96 * *$ & $117.83 * *$ & 0.16 \\
\hline Blocks & 4 & 1.80 & 0.35 & 0.83 & 2.27 & 0.24 & 0.39 & 0.18 & 1.33 \\
\hline Genotype (G) & 1 & $27.17 * *$ & $15.39 * *$ & 1.41 & $145.88 * *$ & $810.06 * *$ & $132.74 * *$ & 2.77 & 1.16 \\
\hline YxG & 1 & $13.00 * *$ & 0.93 & 0.03 & $15.19 * *$ & $118.95 * *$ & $108.53 * *$ & $13.72 * *$ & 3.22 \\
\hline Sowing Time(S) & 3 & $174.25 * *$ & $13.67 * *$ & $37.67 * *$ & $79.30 * *$ & $6.27 * *$ & $22.34 * *$ & 2.79 & $33.43 * *$ \\
\hline YxS & 3 & $22.90 * *$ & 1.00 & 2.10 & 1.94 & $67.32 * *$ & 1.28 & $24.32 * *$ & 0.62 \\
\hline GxS & 3 & $33.12 * *$ & 1.11 & $257.27 * *$ & 1.02 & 3.20 & 1.23 & 1.00 & $13.50 * *$ \\
\hline YxGxS & 3 & $25.77 * *$ & 0.89 & 19.77 *** & 1.25 & 2.94 & $5.39 *$ & 0.64 & 0.01 \\
\hline C.V. $(\%)$ & & 2.65 & 4.30 & 3.99 & 2.77 & 1.38 & 1.58 & 3.39 & 9.52 \\
\hline
\end{tabular}

*Indicates F-test significant at $p<0.05$; **Indicates F-test significant at $p<0.01$.

The oil content can be affected by many factors. It has been reported in previous studies that the oil content of the seed was influenced by many factors including genotype, environmental factors and agricultural activities (Vollman et al., 2007; Guy et al., 2014; Righini, 2018). As a matter of fact, in a previous study indicated that the oil content decreased significantly with temperature increase (Yaniv et al., 1995). It has been reported that sowing time in camelina affected the change of oil content (Urbaniak et al., 2008; Koncius and Karcauskiene, 2010; Schillinger et al., 2012; Katar et al., 2012a; Katar et al., 2012b; Koc, 2014). The delay of the sowing time, the flowering, seed filling and maturing period shifts towards the warmer period. As a result, the oil content decreased due to the temperature increase. As a matter of fact, when the ecological data in the research area are evaluated; In July and August, which are the flowering and seed filling period, especially in 2018, higher temperature, humidity and day length and lower rainfall were observed (Figure $1)$.

Some studies indicated that camelina oil content is greater under cooler conditions (Yaniv et al., 1995; Kirkhus et al., 2013; Zanetti et al., 2017). It has been reported that the temperature increases in the flowering and maturing periods decrease the oil content in oil plants (Kirkhus et al., 2013). This decrease in oil content is important in terms of showing how important the sowing time is on the oil content. The fact that a different level of decrease in the oil content of the genotypes with the delay of the sowing indicates that if the seed cannot be sown in time for various reasons the genotypes that have the potential to minimize the effect of the decrease in the oil content caused by the delay. As a result of this research, the decrease in oil content in the PI-650142 genotype is less than that of the PI-304269 genotype confirms this situation.

\section{Saturated Fatty Acids Compositions}

Palmitic and stearic fatty acids were investigated as saturated fatty acids in the study (Table 1 and 2). The palmitic acid content was significantly $(p<0.01)$ affected by year, genotype and sowing time. The stearic acid content was significantly $(p<0.01)$ affected by year, sowing time, genotype $\mathrm{x}$ sowing time interaction and year $\mathrm{x}$ genotype $\mathrm{x}$ sowing time interaction (Table 2).

The palmitic acid content increased when the sowing time was delayed, and the rate which was $6.04 \%$ at the $1 \mathrm{st}$ sowing time increased to $7.08 \%$ at the 4 th sowing time. The stearic acid content decreases as the sowing time delays, in contrast to the palmitic acid content, and the stearic acid content decreased from $3.15 \%$ at the first sowing time to $2.04 \%$ at the 4 th sowing time. The palmitic acid content is $7.42 \%$ in the first year and $5.87 \%$ in the second year, the change between the genotypes is very limited, $6.55 \%$ in the PI-650142 genotype and $6.75 \%$ in the PI-304269 genotype. It can be also said that the change in the stearic acid content is limited; in this effect sowing times are more obvious than the years. As a matter of fact, the stearic acid content is $2.49 \%$ in the first year and $2.86 \%$ in the second year and has experienced a minimal change. When the sowing time $x$ genotype interaction is evaluated; although the highest stearic acid ratio was obtained at the 1st sowing time of PI-304269 genotype, the lowest stearic acid ratio was obtained at the 4 th sowing time of the same genotype (Table 2). 
Table 2. The average data on oil content and palmitic and stearic saturated fatty acid content of two camelina genotypes evaluated under different sowing times

\begin{tabular}{|c|c|c|c|c|c|c|c|c|c|}
\hline \multicolumn{10}{|c|}{ Oil Content (\%) } \\
\hline \multirow{2}{*}{ Sowing Times } & \multicolumn{3}{|c|}{ PI-650142 } & \multicolumn{3}{|c|}{ PI-304269 } & \multicolumn{3}{|c|}{ Overall } \\
\hline & 2017 & 2018 & Mean & 2017 & 2018 & Mean & 2017 & 2018 & General Mean \\
\hline $1^{\text {st }}$ Sowing & $35.34 \mathrm{bc}$ & $27.65 \mathrm{e}$ & $31.49 \mathrm{~b}$ & $37.19 \mathrm{a}$ & $34.43 \mathrm{bc}$ & $35.81 \mathrm{a}$ & $36.26 \mathrm{a}$ & $31.04 \mathrm{c}$ & $33.65 \mathrm{a}$ \\
\hline $2^{\text {nd }}$ Sowing & $32.89 \mathrm{~cd}$ & $24.97 \mathrm{ef}$ & $28.93 \mathrm{c}$ & $36.95 \mathrm{ab}$ & $25.43 \mathrm{ef}$ & $31.19 \mathrm{~b}$ & $34.92 \mathrm{a}$ & $25.20 \mathrm{~d}$ & $30.06 \mathrm{~b}$ \\
\hline $3^{\text {rd }}$ Sowing & $31.43 \mathrm{~d}$ & $24.26 \mathrm{fg}$ & $27.84 \mathrm{c}$ & $34.71 \mathrm{abc}$ & $22.04 \mathrm{gh}$ & $28.37 \mathrm{c}$ & $33.07 \mathrm{~b}$ & $23.15 \mathrm{e}$ & $28.11 \mathrm{c}$ \\
\hline $4^{\text {th }}$ Sowing & $31.30 \mathrm{~d}$ & $23.86 \mathrm{fg}$ & $27.58 \mathrm{c}$ & $31.00 \mathrm{~d}$ & $20.46 \mathrm{~h}$ & $25.73 \mathrm{~d}$ & $31.15 \mathrm{c}$ & $22.16 \mathrm{e}$ & $26.65 \mathrm{~d}$ \\
\hline Mean & $32.74 \mathrm{~b}$ & $25.19 \mathrm{c}$ & $28.96 \mathrm{~b}$ & $34.96 \mathrm{a}$ & $25.59 \mathrm{~b}$ & $30.28 \mathrm{a}$ & $33.85 \mathrm{a}$ & $25.39 \mathrm{~b}$ & 29.62 \\
\hline \multicolumn{10}{|c|}{ Palmitic Acid Content (\%) } \\
\hline \multirow{2}{*}{ Sowing Times } & \multicolumn{3}{|c|}{ PI-650142 } & \multicolumn{3}{|c|}{ PI-304269 } & \multicolumn{3}{|c|}{ Overall } \\
\hline & 2017 & 2018 & Mean & 2017 & 2018 & Mean & 2017 & 2018 & General Mean \\
\hline $1^{\text {st }}$ Sowing & 6.60 & 5.05 & 5.82 & 6.98 & 5.51 & 6.25 & 6.79 & 5.28 & $6.04 \mathrm{c}$ \\
\hline $2^{\text {nd }}$ Sowing & 7.42 & 5.60 & 6.51 & 7.62 & 5.68 & 6.65 & 7.52 & 5.64 & $6.58 \mathrm{~b}$ \\
\hline $3^{\text {rd }}$ Sowing & 7.63 & 6.17 & 6.90 & 7.69 & 6.12 & 6.90 & 7.66 & 6.14 & $6.90 \mathrm{ab}$ \\
\hline $4^{\text {th }}$ Sowing & 7.74 & 6.18 & 6.96 & 7.70 & 6.68 & 7.19 & 7.72 & 6.43 & $7.08 \mathrm{a}$ \\
\hline Mean & 7.35 & 5.75 & $6.55 \mathrm{~b}$ & 7.50 & 6.00 & $6.75 \mathrm{a}$ & $7.42 \mathrm{a}$ & $5.87 \mathrm{~b}$ & 6.04 \\
\hline \multicolumn{10}{|c|}{ Stearic Acid Content (\%) } \\
\hline \multirow{2}{*}{ Sowing Times } & \multicolumn{3}{|c|}{ PI-650142 } & \multicolumn{3}{|c|}{ PI-304269 } & \multicolumn{3}{|c|}{ Overall } \\
\hline & 2017 & 2018 & Mean & 2017 & 2018 & Mean & 2017 & 2018 & General Mean \\
\hline $1^{\text {st }}$ Sowing & $2.68 \mathrm{def}$ & 3.04 bcd & $2.86 \mathrm{c}$ & $3.51 \mathrm{a}$ & $3.40 \mathrm{ab}$ & $3.45 \mathrm{a}$ & 3.09 & 3.21 & $3.15 \mathrm{a}$ \\
\hline $2^{\text {nd }}$ Sowing & $2.66 \mathrm{ef}$ & $2.87 \mathrm{de}$ & $2.76 \mathrm{~cd}$ & 2.99 cde & $3.34 \mathrm{abc}$ & $3.16 \mathrm{~b}$ & 2.82 & 3.10 & $2.96 \mathrm{~b}$ \\
\hline $3 r^{d}$ Sowing & $2.37 \mathrm{fg}$ & $2.72 \mathrm{def}$ & $2.54 \mathrm{de}$ & $2.09 \mathrm{gh}$ & 2.99 cde & $2.54 \mathrm{de}$ & 2.23 & 2.85 & $2.54 \mathrm{c}$ \\
\hline $4^{\text {th }}$ Sowing & $2.16 \mathrm{gh}$ & $2.69 \mathrm{def}$ & $2.42 \mathrm{e}$ & 1.471 & $1.85 \mathrm{~h}$ & $1.66 \mathrm{f}$ & 1.81 & 2.26 & $2.04 \mathrm{~d}$ \\
\hline Mean & 2.47 & 2.83 & 2.65 & 2.51 & 2.89 & 2.70 & $2.49 \mathrm{~b}$ & $2.86 \mathrm{a}$ & 2.67 \\
\hline
\end{tabular}

Means followed by different letter within each column are significantly different at $p<0.05$.

The fatty acid content in camelina oil depends mainly on the varieties and on the conditions under which the crop was grown (Ibrahim and Habbasha, 2015). If a general evaluation is made considering the results of the two years; it can be said that the rate of palmitic acid decreases and the rate of stearic acid increases as the seed sowing time delays. This increase and decrease between palmitic and stearic acid are actually expected. Because these fatty acids compete with each other, it is a natural situation that if one increases, the other decreases. Thus, the findings obtained in this study confirm the contrasting relationship between two saturated fatty acids. It has been reported that the saturated fatty acid content in camelina oil varies between 9.10-10.80\% (Toncea et al., 2013) and the palmitic acid content varies between $6.90-11.00 \%$ (Sipalova et al., 2011).

Environmental factors, especially genotype and cultivation applications cause the rate of palmitic or stearic acids in the seed to change. The limits of this change determine the severity of the influencing factors. When the variation of palmitic and stearic acid ratios according to years and sowing time is evaluated; the changes in both saturated fatty acids over the years remain at a more limited level compared to the time of sowing. This finding, obtained in the study, proves that agricultural practices such as sowing times may change the fatty acid composition as well as environmental factors.

\section{Unsaturated Fatty Acid Compositions}

Oleic, linoleic, linolenic, eicosenoic and erucic fatty acids were evaluated as unsaturated fatty acids in the study (Table 1 and 3). The oleic, linoleic and linolenic acid content was significantly $(p<0.01)$ affected by year, genotype, sowing time and year $\mathrm{x}$ genotype interaction. The linoleic acid content was significantly affected by year $\mathrm{x}$ sowing time interaction $(p<0.01)$ and linolenic acid content was significantly affected by year $\mathrm{x}$ genotype $\mathrm{x}$ sowing time interaction $(p<0.05)$ (Table 1$)$.

The Oleic acid content increased when the sowing time was delayed, and the rate which was $16.63 \%$ at the $1^{\text {st }}$ sowing time increased to $18.84 \%$ at the $4^{\text {th }}$ sowing time. In contrast to oleic acid, linoleic and linolenic acid content decreased as the sowing time was delayed. Linoleic and linolenic acid content were respectively $25.16 \%$ and $31.69 \%$ at the 1 st sowing time and $24.83 \%$ and $29.57 \%$ at the $4^{\text {th }}$ sowing time, respectively.

When evaluated on yearly basis; oleic acid ratio decreased from $19.07 \%$ to $15.96 \%$ with a decrease of $16.31 \%$. Linoleic and linolenic acid content increased by $21.50 \%$ and $2.19 \%$, respectively, and linoleic acid content increased from $21.84 \%$ to $27.82 \%$ and linolenic acid content from $30.34 \%$ to $31.02 \%$.

The oleic $(18.14 \%)$ and linolenic $(31.30 \%)$ acid content in the PI-650142 genotype is higher than the PI304269 genotype (oleic $16.90 \%$ and linolenic $30.07 \%$ ). Contrary to the oleic and linoleic acid content, the linoleic acid content is lower in the PI-650142 genotype (23.53\%) than the PI-304269 genotype (26.13\%). 
Table 3. The average data of oleic, linoleic, linolenic, eicosenoic and erusic unsaturated fatty acids content of two camelina genotypes evaluated under different sowing times

\begin{tabular}{|c|c|c|c|c|c|c|c|c|c|}
\hline \multicolumn{10}{|c|}{ Oleic Acid (18:1; n-9) Content (\%) } \\
\hline \multirow{2}{*}{ Sowing Times } & \multicolumn{3}{|c|}{ PI-650142 } & \multicolumn{3}{|c|}{ PI-304269 } & \multicolumn{2}{|c|}{ Overall } & \multirow{2}{*}{ Mean } \\
\hline & 2017 & 2018 & Mean & 2017 & 2018 & Mean & 2017 & 2018 & \\
\hline $1^{\text {st }}$ Sowing & 18.38 & 15.77 & 17.07 & 17.74 & 14.62 & 16.18 & 18.06 & 15.19 & $16.63 \mathrm{c}$ \\
\hline $2^{\text {nd }}$ Sowing & 18.97 & 15.93 & 17.45 & 17.84 & 14.69 & 16.26 & 18.41 & 15.31 & $16.86 \mathrm{c}$ \\
\hline $3^{\mathrm{rt}}$ Sowing & 19.74 & 17.33 & 18.54 & 18.68 & 15.25 & 16.97 & 19.21 & 16.29 & $17.75 \mathrm{~b}$ \\
\hline $4^{\text {th }}$ Sowing & 20.89 & 18.11 & 19.50 & 20.34 & 16.00 & 18.17 & 20.62 & 17.06 & $18.84 \mathrm{a}$ \\
\hline Mean & $19.49 \mathrm{a}$ & $16.78 \mathrm{c}$ & $18.14 \mathrm{a}$ & $18.65 \mathrm{~b}$ & $15.14 \mathrm{~d}$ & $16.90 \mathrm{~b}$ & $19.07 \mathrm{a}$ & $15.96 \mathrm{~b}$ & 17.52 \\
\hline \multicolumn{10}{|c|}{ Linoleic Acid (18:2; n-6) Content (\%) } \\
\hline \multirow{2}{*}{ Sowing Times } & \multicolumn{3}{|c|}{ PI-650142 } & \multicolumn{3}{|c|}{ PI-304269 } & \multicolumn{2}{|c|}{ Overall } & \multirow{2}{*}{ Mean } \\
\hline & 2017 & 2018 & Mean & 2017 & 2018 & Mean & 2017 & 2018 & \\
\hline $1^{\text {st }}$ Sowing & 19.28 & 28.71 & 23.99 & 22.77 & 29.87 & 26.32 & $21.02 \mathrm{f}$ & $29.29 \mathrm{a}$ & $25.16 \mathrm{a}$ \\
\hline $2^{\text {nd }}$ Sowing & 19.82 & 26.70 & 23.26 & 23.69 & 29.07 & 26.38 & $21.75 \mathrm{e}$ & $27.89 \mathrm{~b}$ & $24.82 \mathrm{ab}$ \\
\hline $3^{\text {rd }}$ Sowing & 19.87 & 26.63 & 23.25 & 23.78 & 27.76 & 25.77 & $21.82 \mathrm{e}$ & $27.19 \mathrm{bc}$ & $24.51 \mathrm{~b}$ \\
\hline $4^{\text {th }}$ Sowing & 21.20 & 26.02 & 23.61 & 24.31 & 27.78 & 26.04 & $22.76 \mathrm{~d}$ & $26.90 \mathrm{c}$ & $24.83 \mathrm{ab}$ \\
\hline Mean & $20.04 \mathrm{~d}$ & $27.01 \mathrm{~b}$ & $23.53 b$ & $23.64 \mathrm{c}$ & $28.62 \mathrm{a}$ & $26.13 \mathrm{a}$ & $21.84 \mathrm{~b}$ & $27.82 \mathrm{a}$ & 24.83 \\
\hline \multicolumn{10}{|c|}{ Linolenic Acid (18:3; n-3) Content (\%) } \\
\hline \multirow{2}{*}{ Sowing Times } & \multicolumn{3}{|c|}{ PI-650142 } & \multicolumn{3}{|c|}{ PI-304269 } & \multicolumn{2}{|c|}{ Overall } & \multirow{2}{*}{ Mean } \\
\hline & 2017 & 2018 & Mean & 2017 & 2018 & Mean & 2017 & 2018 & \\
\hline $1^{\text {st }}$ Sowing & $32.50 \mathrm{ab}$ & $31.80 \mathrm{a}-\mathrm{d}$ & 32.15 & $29.67 \mathrm{efg}$ & $32.78 \mathrm{a}$ & 31.22 & 31.09 & 32.29 & $31.69 \mathrm{a}$ \\
\hline $2^{\text {nd }}$ Sowing & $31.86 \mathrm{abc}$ & $31.14 \mathrm{a}-\mathrm{e}$ & 31.50 & $29.51 \mathrm{efg}$ & $31.51 \mathrm{a}-\mathrm{d}$ & 30.51 & 30.68 & 31.33 & $31.00 \mathrm{~b}$ \\
\hline $3^{\text {rd }}$ Sowing & $31.47 \mathrm{a}-\mathrm{d}$ & $30.93 b-f$ & 31.20 & $29.32 \mathrm{fg}$ & $30.17 \mathrm{def}$ & 29.75 & 30.40 & 30.55 & $30.47 \mathrm{~b}$ \\
\hline $4^{\text {th }}$ Sowing & $30.21 \mathrm{c}-\mathrm{f}$ & $30.46 \mathrm{c}-\mathrm{f}$ & 30.33 & $28.20 \mathrm{~g}$ & $29.40 \mathrm{fg}$ & 28.80 & 29.21 & 29.93 & $29.57 \mathrm{c}$ \\
\hline Mean & $31.51 \mathrm{a}$ & $31.08 \mathrm{a}$ & $31.30 \mathrm{a}$ & $29.17 \mathrm{~b}$ & $30.97 \mathrm{a}$ & $30.07 \mathrm{~b}$ & $30.34 \mathrm{~b}$ & $31.02 \mathrm{a}$ & 30.68 \\
\hline \multicolumn{10}{|c|}{ Eicosenoic Acid (20:1; n-9) Content (\%) } \\
\hline \multirow{2}{*}{ Sowing Times (S) } & \multicolumn{3}{|c|}{ PI-650142 } & \multicolumn{3}{|c|}{ PI-304269 } & \multicolumn{2}{|c|}{ Overall } & \multirow{2}{*}{ Mean } \\
\hline & 2017 & 2018 & Mean & 2017 & 2018 & Mean & 2017 & 2018 & \\
\hline $1^{\text {st }}$ Sowing & 16.55 & 12.27 & 14.41 & 15.98 & 12.41 & 14.19 & $16.26 \mathrm{a}$ & $12.34 \mathrm{e}$ & 14.30 \\
\hline $2^{\text {nd }}$ Sowing & 16.23 & 12.71 & 14.47 & 15.62 & 13.69 & 14.66 & $15.93 \mathrm{a}$ & $13.20 \mathrm{de}$ & 14.56 \\
\hline $3^{\text {rd }}$ Sowing & 16.21 & 13.72 & 14.97 & 15.32 & 13.87 & 14.59 & $15.76 \mathrm{ab}$ & $13.79 \mathrm{~cd}$ & 14.78 \\
\hline $4^{\text {th }}$ Sowing & 15.18 & 15.37 & 15.27 & 14.44 & 15.18 & 14.81 & $14.81 \mathrm{bc}$ & $15.27 \mathrm{ab}$ & 15.04 \\
\hline Mean & $16.04 \mathrm{a}$ & $13.52 \mathrm{c}$ & 14.78 & $15.34 \mathrm{~b}$ & $13.79 \mathrm{c}$ & 14.56 & $15.69 \mathrm{a}$ & $13.65 \mathrm{~b}$ & 14.67 \\
\hline & & & rusic Ac & $(22: 1 ; n-9)$ & ontent (\% & & & & \\
\hline & & $\mathrm{I}-650142$ & & & {$[-304269$} & & & & \\
\hline Sowing Times & 2017 & 2018 & Mean & 2017 & 2018 & Mean & 2017 & 2018 & Mean \\
\hline $1^{\text {st }}$ Sowing & 1.93 & 2.10 & $2.02 \mathrm{a}$ & 1.70 & 1.69 & $1.69 \mathrm{~b}$ & 1.82 & 1.89 & $1.86 \mathrm{a}$ \\
\hline $2^{\text {nd }}$ Sowing & 1.60 & 1.63 & $1.62 \mathrm{~b}$ & 1.69 & 1.54 & $1.62 \mathrm{~b}$ & 1.65 & 1.59 & $1.62 \mathrm{~b}$ \\
\hline $3^{\text {rd }}$ Sowing & 1.38 & 1.45 & $1.42 \mathrm{bc}$ & 1.65 & 1.50 & $1.58 \mathrm{bc}$ & 1.52 & 1.48 & $1.50 \mathrm{~b}$ \\
\hline $4^{\text {th }}$ Sowing & 0.78 & 1.01 & $0.90 \mathrm{~d}$ & 1.31 & 1.30 & $1.30 \mathrm{c}$ & 1.04 & 1.16 & $1.10 \mathrm{c}$ \\
\hline Mean & 1.43 & 1.55 & 1.49 & 1.59 & 1.51 & 1.55 & 1.51 & 1.53 & 1.52 \\
\hline
\end{tabular}

Means followed by different letter within each column are significantly different at $P<0.05$.

When oleic, linoleic and linolenic acid contents are evaluated in terms of year $\mathrm{x}$ genotype interaction; the oleic, linoleic and linolenic acid ratios were $19.49 \%$, $20.04 \%$ and $31.51 \%$ in the first year PI-650142 genotype, respectively, while in the PI-304269 genotype it was $18.65 \%, 23.64 \%$ and $29.17 \%$. In the second year, it was $16.78 \%, 27.01 \%$ and $31.08 \%$ in the PI-650142 genotype, respectively, while it was $15.14 \%, 28.62 \%$ and $30.97 \%$ in the PI-304269 genotype.

Eicosenoic acid content was significantly affected $(p<0.01)$ by year, year $\mathrm{x}$ genotype interaction and year $\mathrm{x}$ sowing time interaction (Table 1). Eicosenoic acid content was $15.69 \%$ in the first year and $13.65 \%$ in the second year. In both camelina genotypes; eicosenoic acid content in the first year (16.04\% in PI-650142 and $15.34 \%$ in PI304269 ) is higher than the 2 nd year (13.52\% in PI-650142 and $13.79 \%$ in PI-304269).
Although the eicosenoic acid content decreased in the first year as the sowing time was delayed, the second year showed a reverse situation. Thus; while the eicosenoic acid content was $16.26 \%$ at the 1 st sowing time in 2017 , it decreased to $14.81 \%$ at the 4th sowing time, and the eicosenoic acid content increased from $12.34 \%$ at the first sowing time to $15.27 \%$ at the 4 th sowing time in the second year (Table 3).

The erusic acid content was significantly affected $(p<0.01)$ by Sowing time and genotype $\mathrm{x}$ sowing time interaction (Table 1). The erusic acid content decreased as the time of sowing was delayed. The highest erusic acid content $(1.86 \%)$ was in the 1 st sowing time and the lowest erusic acid content $(1.10 \%)$ was at the $4^{\text {th }}$ sowing time. 
a)

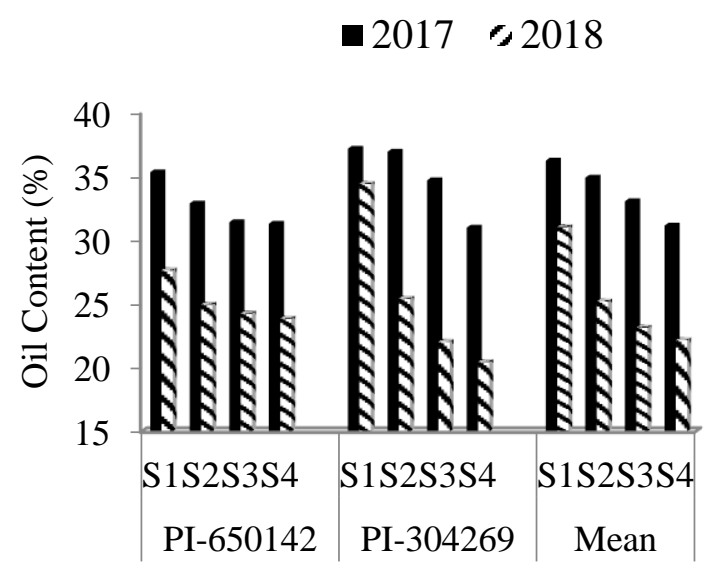

Figure 2a. The scatter plot of oil content according to genotype and sowing time interactions ( $\mathrm{S}=$ Sowing time)

Since the sowing time was delayed, the erusic acid content decreased in both camelina genotypes. The lowest erusic acid content in PI-650142 and P1-304269 genotypes were obtained during the $1^{\text {st }}$ sowing time with $0.90 \%$ and $1.30 \%$, respectively (Table 3 ).

The increase and decrease in oleic, linoleic and linolenic acid content depending on years and sowing time shows that there is a balanced situation between these fatty acids. In general, some studies showed negative correlations between the levels of oleic and linoleic (as well as linolenic if present in the seed oil) with the degree b)

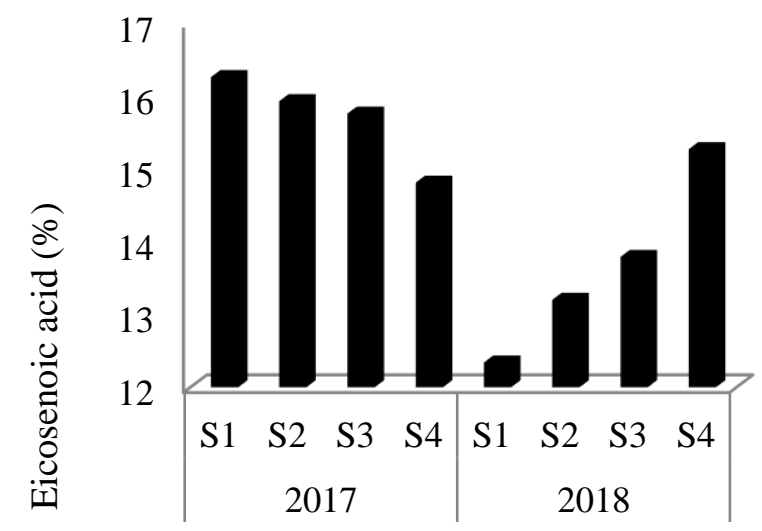

Figure 2b. The scatter plot of eicosenoic acid content by year and sowing time interactions ( $\mathrm{S}=$ Sowing time)

of unsaturated decreasing when the crops were grown at higher temperatures (Yaniv et al., 1995; Deng and Scarth, 1998). Therefore, despite the decrease in one, an increase in the other is an expected result. As a matter of fact, according to the data obtained from the research, it was determined that there was a negative relationship between these fatty acids as a result of the correlation analysis conducted to determine the relationships between oleic and linoleic acid $\left(r^{2}=0.2036\right)$ and also oleic and linolenic acid $\left(r^{2}=0.9493\right)$ (Figure 3$)$. a)

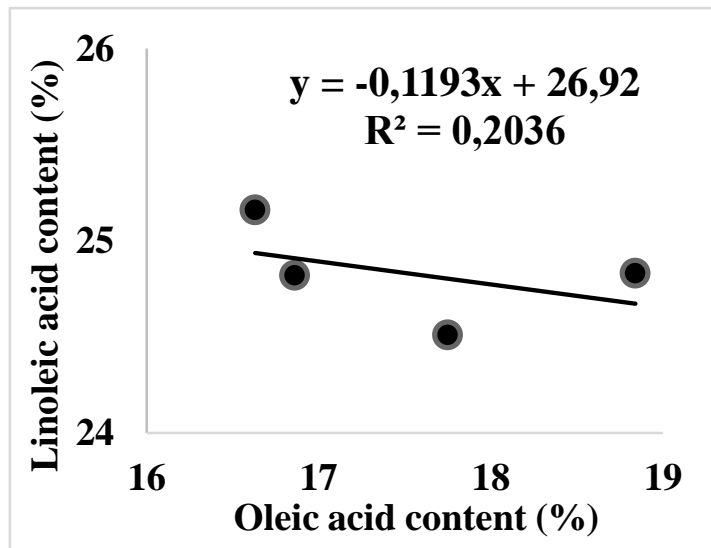

b)

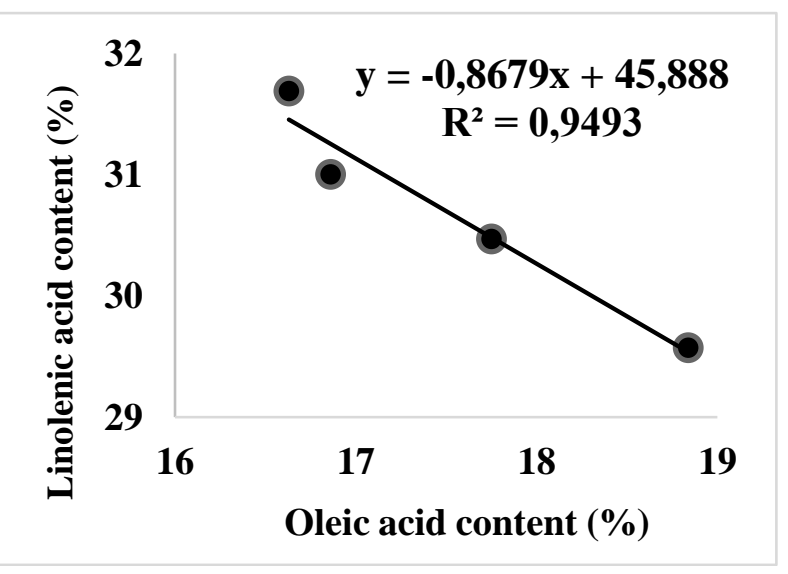

Figure 3. Graph of bilateral relations between oleic acid and linoleic and linolenic acid. a) Oleic acid and linoleic acid and b) Oleic acid and linolenic acid 
However, the decrease in oleic acid content did not reflect as a one to one increase in linoleic and also linolenic acid content. However, this result is important in terms of showing the effect of seed sowing time, genotype and interaction between them on oleic and linoleic acid and also linolenic acid content. It has been also reported that many factors affect the change of oleic, linoleic ad linolenic acid content in camelina seed oil. For example, a study (Katar et al., 2012a) reported that the content of oleic, linoleic and linolenic acid in camelina seed varies between $16.03-17.59 \%, 18.45-23.36 \%$ and $24.86-32.26 \%$, respectively, depending on sowing times.

This may be because the increase in air temperatures affecting the change in the composition of fatty acids is greater during the seed filling period. As a matter of fact, when the climate data in the period in which this research was conducted is evaluated, 2018 is a warmer year compared to 2017 and especially in June, which is the flowering and seed filling period, the daily temperature amount is higher and the day length is longer. This difference in climate probably played an important role in changing the content of these fatty acids.

The delay in sowing times had an effect on the eicosenoic acid content in the form of a decrease in the first year, while the second year showed an opposite increase (Figure 2b). However, the evaluation of the effects of eicosenoic content both years and genotypes separately; the eicosenoic acid content was lower than the first year (Table 3). This means; there was an increase in eicosenoic acid content, as environmental factors had more effect than genotype factor, due to the fact that the 2nd year is warmer and the seed filling and maturation period partially coincides with the delay in sowing time.

The reason for the decrease of erusic acid content as the sowing time is delayed; the second year of the research was due to the fact that the seed filling and maturation period came in a warmer period. The content of erusic acid synthesis during seed development is influenced by the temperature regime (Yaniv et al., 1995). As a matter of fact, it was reported in a study that the erucic acid content decreased due to the increase in temperature (Pavlista et al., 2011).

\section{CONCLUSION}

Camelina is a unique plant whose usage area can change according to the fatty acid composition it contains. It is desirable to reduce its high content of polyunsaturated (for example linolenic acid) and very-long-chain fatty acids for to increase camelina oil for biofuel production oleic acid is more suitable for both cooking oil and industrial occupancy, for that reason it is a primary goal to breed high oleic oilseed varieties. However, to be used as edible oil, the erusic acid content have to be reduced to near zero.

The most important factors affecting oil content and fatty acid composition are growing seasons, organic matter content and environmental factors such as temperature, rainfall, day length and humidity in the growing period. These research results show that different genotypes and sowing times significantly affected the oil content and fatty acid composition of camelina in spring growing season. However, the effects of sowing times on the oil content and fatty acid composition of the genotypes showed different severity in both genotypes, and in terms of oil content and fatty acids composition, the genotype factor is a very important factor to be taken into consideration as well as the sowing time. Consequently, in case of delay of sowing time, it is extremely important to perform timely sowing, considering the changes in both the oil content and the composition of the fatty acids. In addition, in case of delayed sowing for any reason, genotypes that can tolerate the effects that may arise due to delay should be preferred. Thus, the losses that may arise can be reduced, albeit partially.

\section{LITERATURE CITED}

Adamsen, FJ. and T.A. Coffelt. 2005. Planting date effects on flowering, seed yield and oil content of rape and crambe cultivars. Ind Crops Prod. 21:293-307.

Anonymous, 2020a. USDA, www.ars-grin.gov. (Accessed September 10, 2020).

Anonymous, 2020b. Samsun Meteorological Stations Records. Samsun.

Anonymous, 2020c. AOCS 5-04 Soxhlet Extraction System, https://www.ankom.com/ product-catalog/ankom-xt15extractor.(Accessed December 20, 2019).

Deng, X. and R. Scarth. 1998. Temperature effects on fatty acid composition during development of low-linolenic oilseed rape (Brassica napus L.). J Am Oil Chem Soc. 75:759-766.

Farré, I. M.J. Robertson, G.H. Walton and S. Asseng. 2002. Simulating phenology and yield response of canola to sowing date in Western Australia using the APSIM model. Aust J Agric Res. 53: 1155-1164.

Garcia-Inza, G.P., Castro, D.N., Hall, A.J. and Rousseaux, M.C. 2014. Responses to temperature of fruit dry weight, oil concentration, and oil fatty acid composition in olive (Olea europaea L. var. 'Arauco'). European J Agron. 54: 107-115.

Gesch, R.W. and S.C. Cermak. 2011. Sowing date and tillage effects on fall-seeded camelina in the Northern Cornbelt. Agron J. 103: 980-987.

Gomez, K.A. andAA.Gomez. 1984. Statistical procedures for agricultural research. 2 ed. New York: John Wiley \& Sons.

Gore, M. and Kurt, O. 2017. Determination of crude oil content and fatty acid composition of different false flax [Camelina sativa (L.) Crantz.] genotypes. J Agri Nature, 20: 201-205.

Guy, S.O., D.J. Wysocki, W.F. Schillinger, T.G. Chastain, R.S. Karow, K. Garland-Campbell and and I.C. Burke. 2014. Camelina: Adaptation and performance of genotypes. Field Crop Res. 155: 224-232.

Ibrahim, F.M. and S.F. Habbasha.2015. Chemical composition, medicinal impacts and cultivation of Camelina (Camelina sativa). Inter J Pharm Tech Res. 8(10):114-122.

Jiang Y., C.D. Caldwell, K.C. Falk. 2014. Camelina seed quality in response to applied nitrogen, genotype and environment. Can J Plant Sci. 94: 971-980.

Katar, D., Y. Arslan and I. Subasi. 2012a. Determination of effect of different sowing dates on oil content and fatty acid composition in Camelina (Camelina sativa (L.) Crantz) under Ankara Ecological Condition. J Tekirdag Agric Fac. 9(3): 84-90.

Katar, D., Y. Arslan and I. Subasi. 2012b. Genotypic variations on yield, yield components and oil quality in some Camelina 
(Camelina sativa (L.) Crantz) genotypes. Turk J Field Crops. 17(2): 105-110.

Kinay, A., G. Yilmaz, S. Ayisigi and S. Dokulen.2019. Yield and quality parameters of winter and summer-sown different camelina (Camelina sativa L.) genotypes. Turk J Field Crops. 24(2): 164-169.

Kirkhus, B., A.R. Lundon, J.E., Haugen, G. Vogt, G.I. Borge and B.I. Henriksen. 2013. Effects of environmental factors on edible oil quality of organically grown Camelina sativa.J Agric Food Chem. 61: 3179-3185.

Koc, N. 2014. Determination of yield and some agronomic properties of false flax (Camelina sativa L. Crantz) at different sowing times [dissertation]. Konya: University of Selcuk (in Turkish).

Koncius, D. and D. Karcauskiene. 2010. The Effect of nitrogen fertilizers, sowing time and seed rate on the productivity of Camelina sativa. Agriculture 97(4): 37-47.

Kurt, O., H. Uysal, A. Demir, U. Ozgur and R. Kilic. 2011. A study on the establishment of adaptability of winter safflower (Carthamus tinctorius L.) genotypes in Samsun ecological conditions. Anadolu JAgric Sci. 26(3): 212-216

Neupane, D., J.K.Q. Solomon, E. Mclennon, J. Davison and T. Lawry. 2019. Sowing date and sowing method influence on camelina cultivars grain yield, oil concentration, and biodiesel production. Food\&Energy Sec. 8(3): 1-17.

Omidi, H., Z. Tahmasebi, H.A.N. Badi, H. Torabi and M. Miransari. 2010. Fatty acid composition of canola (Brassica napus L.), as Affected by agronomical, genotypic and environmental parameters. Comptes Rendus Bio. 333(3): 248-254.

Pavlista, A.D., T.A. Isbell, D.D. Baltenspergerc and G.W. Hergerta. 2011. Planting date and development of springseeded irrigated canola, brown mustard and camelina. Ind Crop and Prod. 33: 451-456.

Popa, M., Anton, G.F., Risnoveane, L., Petcu, E. and Babeanu, N. 2017. The effect of planting date and climatic condition on oil content and fatty acid composition in some Romanian sunflower hybrids. Agro Life Sci J. (6)1: 212-217.

Pritchard, F.M., H.A. Eagles, R.M. Norton, S.A. Salisbury and M. Nicolas 2000. Environmental effects on seed composition of victorian canola. Aust J Exp Agric. 40: 679-685.

Righini, D. 2018. Investigating the effects of temperature on oil quality of Camelina sativa for bio-based applications [dissertation]. Universiy of Bologna.

Righini, D., F. Zanettia, E. Martínez-Forceb, M. Mandriolia, T.G. Gallina-Toschia and A. Montia.2019. Shifting sowing of camelina from spring to autumn enhances the oil quality for bio-based applications in response to temperature and seed carbon stock. Ind Crop Prod. 137: 66-73.
Sainz, R., H.E. Echeverri'a, G.A. Studdert and F.H. Andrade.1999. No-Tillage maize nitrogen uptake and yield: effect of urease inhibitor and application time. Agron J. 91: 950-955.

Schillinger, W.F., D.J. Wysocki, T.G. Chastainc, S.O. Guy and R.S. Karow. 2012. Camelina: Planting Date and method effects on stand establishment and seed yield. Field Crops Res. 130: 138-144.

Schulte, L.R., T. Ballard, T. Samarakoon, L. Yao, P. Vadlani, S. Staggenborg and M. Rezac. 2013. Increased growing temperature reduces content of polyunsaturated fatty acids in four oilseed crops. Ind Crop Prod. 51: 212-219.

Sintim, H.Y., V.D. Zheljazkovg, A.K. Obour, A. Garcia y Garcia and T.K. Foulke. 2016. Evaluating agronomic responses of camelina to seeding date under rain-fed conditions. Agron J. 8: 349-357.

Sipalova, M., T. Losak, J. Hkusek, J. Vollmann, J. Hude, R. Filipcik, M. Macek and S. Kracmar. 2011. Fatty acid composition of Camelina sativa as affected by combined nitrogen and sulphur fertilisation. Afr J Agric Res. 16 (6): 3919-3923.

Toncea, I., D. Necseriu, T. Prisecaru, L.N. Balint, M.I. Ghilvacs and M. Popa. 2013. The seed's and oil composition of camelia-first Romanian cultivar of camelina (Camelina sativa L. Crantz). Roman Biotech Lett. 18(5): 8594-860.

Urbaniak, S.D., C.D. Caldwell, V.D. Zheljazkov, R. Lada and L. Luan. 2008. The effect of cultivar and applied nitrogen on the performance of Camelina sativa L. in the Maritime Provinces of Canada. Can J Plant Sci. 88: 111-119.

Vollmann, J., T. Moritz, C. Kargl, S. Baumgartner and H. Wagentristl. 2007. Agronomic evaluation of camelina genotypes selected for seed quality characteristics. Ind Crop Prod. 26: 270-277.

Weiss, E.A. 2000. Oil Seed Crops. 2nd ed. Oxford, London: Blackwell Science Ltd., 373pp.

Yaniv, Z., D. Schafferman and M. Zur. 1995. The effect of temperature on oil quality and yield parameters of high- and low-erusic acid cruciferae seeds (rape and mustard). Ind Crop Prod. 3: 247-252.

Zanetti, F., C. Eynck, M. Christou, M. Krzyzaniak, D. Righini, E. Alexopoulou, M.J. Stolarski, E.N. Van Loo, D. Puttick and A. Monti. 2017. Agronomic performance and seed quality attributes of camelina (Camelina Sativa L. Crantz) in multi-environment trials across Europe and Canada. Ind Crop Prod. 107: 602-608.

Zubr, J. 2003. Qualitative variation of Camelina sativa seed from different locations. Ind Crop Prod. 17(3): 161-169. 